\title{
Anti-Hyperuricemic, Anti-Inflammatory and Analgesic Effects of Siegesbeckia orientalis L. Resulting from the Fraction with High Phenolic Content
}

Thuy Duong Nguyen ${ }^{1}$, Phuong Thien Thuong ${ }^{2}$, In Hyun Hwang ${ }^{3}$, Thi Kim Huyen Hoang ${ }^{1}$, Minh Khoi Nguyen², Hoang Anh Nguyen ${ }^{1^{*}}$ and MinKyun $\mathrm{Na}^{4^{*}}$

\begin{abstract}
Background: The medicinal plant Siegesbeckia orientalis L. has been commonly used for the treatment of acute arthritis, rheumatism, and gout in Vietnam. However, pharmacological research of this plant associated with gout has not been reported. Anti-hyperuricemic and anti-inflammatory effects were evaluated and observed for the crude ethanol extract (CEE) of S. orientalis. Retention of these biological properties was found in a $n$-butanol-soluble fraction (BuOH fr.) of the extract, and therefore further biological and chemical investigations were undertaken on the $\mathrm{BuOH}$ fr. to support the medical relevance of this plant.

Methods: The aerial part of S. orientalis was obtained in the mountainous region of Vietnam. The crude ethanol extract (CEE) and its $\mathrm{BuOH}$ fr. were prepared from the plant materials. Anti-hyperuricemic activities of the CEE and $\mathrm{BuOH}$ fr. were tested in vivo using the model oxonate-induced hyperuricemia rats through determination of serum uric acid levels and inhibitory effects on xanthine oxidase $(X O)$ in the rat liver. Anti-inflammatory activities of the $\mathrm{BuOH}$ fr. were also evaluated in vivo using carrageenan-induced paw edema and urate-induced synovitis in rats. Active components of the $\mathrm{BuOH}$ fr. were characterized by comparison of HPLC retention time $\left(t_{R}\right)$ and spectroscopic data (UV, ${ }^{1} \mathrm{H}-\mathrm{NMR}$ ) with those of reference compounds.

Results: The CEE of S. orientalis displayed anti-hyperuricemic activity, and the $\mathrm{BuOH}$ fr. was found to be the most active portion of the extract. Further in vivo studies on this fraction showed 31.4\% decrease of serum uric acid levels, $32.7 \%$ inhibition of xanthine oxidase $(\mathrm{XO}), 30.4 \%$ reduction of paw edema volume, symptomatic relief in urate-induced synovitis and significant analgesic effect at the dose of $120 \mathrm{mg} / \mathrm{kg}$, as compared to the corresponding values of the control groups. Chemical analysis of the $\mathrm{BuOH}$ fr. revealed high phenolic content, identified as caffeic acid analogues and flavonones.

Conclusions: This study suggested that anti-hyperuricemic and anti-inflammatory mechanism of S. orientalis is related to XO inhibitory effect of the phenolic components. Our findings support the use of this plant as the treatment of gout and other inflammatory diseases.
\end{abstract}

Keywords: Siegesbeckia orientalis, Anti-hyperuricemic activity, Anti-inflammatory activity, Analgesic activity, Xanthine oxidase, Caffeic acid analogues, Flavonones

\footnotetext{
*Correspondence: anh90tk@yahoo.com; mkna@cnu.ac.kr

'Department of Pharmacology, Hanoi University of Pharmacy, 13 Le Thanh

Tong, Hoan Kiem, Hanoi, Vietnam

${ }^{4}$ College of Pharmacy, Chungnam National University, Yuseong-gu, Daejeon

34134, Republic of Korea

Full list of author information is available at the end of the article
} International License (http://creativecommons.org/licenses/by/4.0/), which permits unrestricted use, distribution, and reproduction in any medium, provided you give appropriate credit to the original author(s) and the source, provide a link to the Creative Commons license, and indicate if changes were made. The Creative Commons Public Domain Dedication waiver (http://creativecommons.org/publicdomain/zero/1.0/) applies to the data made available in this article, unless otherwise stated. 


\section{Background}

The plant Siegesbeckia orientalis L. (syn. S. glutinosa), a member of Asteraceae, is widely distributed in Vietnam and other South-East Asian countries [1,2]. The aerial part of this plant has been used for treating various inflammatory diseases, such as neurasthenia, insomnia, impetigo, furuncle, wound, and burn [2]. Being known as a Vietnamese indigenous medicine "hy-thiem", this plant has been applied in a series of traditional remedies for the treatment of acute arthritis, rheumatism, inflammation, and especially gout and pain [1, 3, 4]. Although biological potential of $S$. orientalis has been previously investigated, the interest was limited to anti-inflammatory and analgesic activities of either whole herbal extract [5] or kirenol [2], which is an ent-pimarane type diterpene identified from this plant and commonly encountered from the same genus Aster [6-8]. Furthermore, a recent in vitro and in vivo study on the anti-inflammatory mechanism of $S$. orientalis demonstrated that its ethanol extract suppresses mitogen-activated protein kinases (MAPKs)- and NF-кB-dependent pathways [9]. Given that inflammatory response is a key step in the onset of gout symptoms [10], anti-inflammatory effects were thought to be responsible for traditional utilization of $S$. orientalis as a part of symptomatic treatment of this disorder.

Xanthine oxidase is an enzyme converting xanthine and hypoxanthine into uric acid. A high level of serum uric acid (hyperuricemia) is a well-known major cause of gout, and this metabolic syndrome is closely related to inflammatory responses [10]. Deposition of monosodium urate crystals in a joint could lead to an acute inflammatory pain. Phytochemical studies of S. orientalis identified various secondary metabolites, which include sesquiterpenoids $[11,12]$, diterpenoids $[6-8,13]$, and caffeic acid and rutin [14]. It is notable that in vitro xanthine oxidase (XO) inhibitory activities of caffeic acid and its analogues were reported previously [14-16], while rutin exhibited the anti-hyperuricemic effect in mice mediated by XO inhibition in vivo, but not in vitro $[17,18]$. Our preliminary screening also confirmed that the ethanol extract of $S$. orientalis was a potent inhibitor of $\mathrm{XO}$ among more than 300 Vietnamese medicinal plants. Therefore, it was supposed that $S$. orientalis could have dual role in treatment of gout which related to both hypouricemic and antiinflammatory activity. Based on a literature search, kirenol was suggested to be the main active compound which was responsible for the anti-inflammatory activity of $S$. orientalis [2]. To our knowledge, this compound, however, has not been observed for biological activities with regard to $\mathrm{XO}$ inhibition. Important active constituents involved in XO inhibition activity of $S$. orientalis therefore remain to be determined.

The present study evaluates anti-hyperuricemic and anti-inflammatory effects of $S$. orientalis extract using well-established animal models. Taking into consideration both anti-inflammatory and XO inhibitory effects, we focused on flavonoids and other phenolic compounds which are extensively studied and well-known antioxidants as potential phytochemical agents for treating diseases mediated by free radicals, including inflammation and gout $[19,20]$.

\section{Methods}

\section{Chemicals and reagents}

All the chemicals and reagents used for in vivo tests were of biological grade purchased from Sigma Aldrich (St Louis, MO, USA): xanthine 99-100\% (Cat. XO626-25G; Lot\#/Batch\# 097 K5307), carrageenan (C1013-100G; Pcode 100,160,665); uric acid ( $>=99 \%$, crystalline, U2625); oxonic acid potassium salt (97\%; 156,124-100G); xanthine oxidase, from bovine milk (X1875-50UN; 1,000,877,910). Solvents for extraction and fractionation were of industrial grade purchased from a licensed chemical company in Hanoi, Vietnam, and used without purification.

\section{Plant material}

The aerial parts of Siegesbeckia orientalis L. (Asteraceae) were collected in the mountainous region of Hoa Binh province, in the North of Vietnam. The plant was authenticated by Prof. Tran Van On, Department of Botany, Hanoi University of Pharmacy. A voucher specimen (VDL-HT01) has been deposited at the Herbarium of the Department of Pharmaceutical Analysis and Standardization, Vietnam National Institute of Medicinal Materials, Hanoi, Vietnam.

\section{Preparation of extraction and fractionation}

The dried plant material $(5 \mathrm{~kg})$ was extracted three times with $96 \%$ ethanol $(\mathrm{EtOH})$ at room temperature for 9 days. The solution was filtered and combined, and the organic solvent was removed under reduced pressure to give a crude ethanol extract (CEE, $180 \mathrm{~g}$ ). A part of the CEE (150 g) was suspended in water $(1 \mathrm{~L})$ and then successively partitioned with $n$-hexane (Hex), ethyl acetate (EtOAc), and $n$-butanol $(\mathrm{BuOH})$ (each $1 \mathrm{~L})$. The organic solvents and water were evaporated to yield Hex- (44 g), EtOAc- (33 g), and $\mathrm{BuOH}$-soluble (30 g) fractions, and the remaining water soluble fraction $(31 \mathrm{~g})$.

\section{Animals}

The adult male Wistar rats (8 weeks old, weighing $140 \pm 10 \mathrm{~g}$ ) were obtained from Animal Facilities, Research Center for Medicine and Pharmacy, Vietnam Military Medical University (Hanoi, Vietnam). Animals were used and processed according to the suggested ethical guidelines for the care of laboratory animals [21], and the experimental protocols in this study were 
approved by the Scientific and Ethical Committee of Hanoi University of Pharmacy (156/DHN-QD). The rats were acclimatized at least 7 days to adapt to their environment before any experimental manipulation. They were housed in $612 \times 345 \times 216 \mathrm{~mm}$ cages (Tecniplast 2000P) in an animal room (Department of Pharmacology, Hanoi University of Pharmacy) with a temperature of $24-26{ }^{\circ} \mathrm{C}$, humidity of $55-60 \%$, regular $12 / 12 \mathrm{~h}$ light/ dark cycle (7:00 a.m. - 7:00 p.m.), and access to standard laboratory diet and tap water freely until used for experiments. General health status of the rats was monitored on alternate days, and no adverse events were recorded during the housing period. At the beginning of each experiment, body weight of the animals ranged from 180 to $220 \mathrm{~g}$. All the samples from animals subjected to the treatments were included in the data analysis.

\section{Evaluation of anti-hyperuricemic effect Drug administration}

Each test sample of $\mathrm{CEE}$ and $\mathrm{BuOH}$ fraction was suspended in $0.5 \%$ sodium carboxymethylcellulose (CMC-Na). Food, but not water, was withdrawn from the animals $2 \mathrm{~h}$ prior to drug administration. Based on the Vietnamese traditional usage of "hy-thiem", rats were given the CEE at 300, 600, $1200 \mathrm{mg} / \mathrm{kg}$ and the $\mathrm{BuOH}$ fraction at $120 \mathrm{mg} / \mathrm{kg}$ once a day for five consecutive days. Rats in the negative control group were orally administrated with $0.5 \%$ CMC-Na only, while those of the positive control group were given allopurinol at $10 \mathrm{mg} / \mathrm{kg}$.

\section{Animal hyperuricemia model}

Hyperuricemia of rats was induced by potassium oxonate, an uricase inhibitor [22]. In brief, potassium oxonate was suspended in $0.5 \% \mathrm{CMC}-\mathrm{Na}$. One hour before administration of the test samples, rats were intraperitoneally injected with the freshly prepared potassium oxonate suspension at the dose of $250 \mathrm{mg} / \mathrm{kg}$ to increase their serum uric acid levels. Whole blood samples were collected from the tail vein of the rats $1 \mathrm{~h}$ after the final administration of tested compounds. Blood was allowed to clot for approximately $1 \mathrm{~h}$ at room temperature and then centrifuged at $3500 \mathrm{rpm}$ for $5 \mathrm{~min}$ to obtain the serum, which was stored at $-20{ }^{\circ} \mathrm{C}$ until used.

\section{Determination of blood uric acid levels}

Serum uric acid levels were determined by the phosphotungstic acid method [23].

\section{Enzyme preparation from rat liver}

Rat liver was rapidly excised and homogenized in an icecold $50 \mathrm{mM}$ potassium phosphate buffer $(\mathrm{pH}$ 8.0). The homogenate was centrifuged at $3000 \times g$ for $10 \mathrm{~min}$ at $4{ }^{\circ} \mathrm{C}$, and then lipid layer was carefully removed. The resulting supernatant was further centrifuged at $10000 \times g$ for
$60 \mathrm{~min}$ at $4{ }^{\circ} \mathrm{C}$. The supernatant obtained from the final centrifugation was used to detect $\mathrm{XO}$ activity.

\section{Assay for XO inhibition in rat liver}

Enzyme activity of $\mathrm{XO}$ was assayed by monitoring uric acid formation using the spectrophotometric method as described elsewhere [24]. Briefly, a reaction was started by adding $100 \mu \mathrm{L}$ of the supernatant to a phosphate buffer solution ( $\mathrm{pH}$ 7.5) containing $0.12 \mathrm{mM}$ xanthine and $0.192 \mathrm{mM}$ EDTA. The mixture (total $5.0 \mathrm{~mL}$ ) was incubated for $30 \mathrm{~min}$ at $37^{\circ} \mathrm{C}$, and the reaction was terminated by the addition of $1 \mathrm{M} \mathrm{HCl}(0.5 \mathrm{~mL})$. The production of uric acid was determined by measuring UV absorbance at $290 \mathrm{~nm}$. The XO activities were expressed as mmol of produced uric acid per minute per gram protein. Protein concentration was determined by the Lowry method [25] using bovine serum albumin as a standard.

\section{Evaluation of anti-inflammatory effect Drug administration}

Rats were randomly divided into 3 groups $(n=8$ for each): negative control, positive control, and test sample $(\mathrm{BuOH}$ fraction). Indomethacin, a nonsteroidal antiinflammatory drug, was used as a reference compound for the positive control group. Each sample of $\mathrm{BuOH}$ fraction and indomethacin was dissolved/suspended in $0.5 \% \mathrm{CMC}-\mathrm{Na}$, and orally given to rats at the dose of $120 \mathrm{mg} / \mathrm{kg}$ and $10 \mathrm{mg} / \mathrm{kg}$ body weight, respectively. The rats in the negative control group were orally administrated with $0.5 \%$ CMC-Na only. Volume of administration was identical for all rats in three groups.

\section{Carrageenan-induced rat paw edema}

Paw edema test was performed according to the previously described carrageenan-induced method [26] with some modification. Briefly, $1 \mathrm{~h}$ after the drug administration, paw edema was induced by injecting $0.1 \mathrm{~mL}$ of $1 \%$ $(w / v)$ carrageenan in buffer saline into the plantar surface of the right hind paw in all rats. The paw was marked in order to immerse it to the same extent in the measurement chamber. Volume of the rat paws was measured using a plethysmometer (Ugo Bisile, Italy) immediately before the carrageenan subplantar injection and at intervals of 1,3 , and $5 \mathrm{~h}$. The assessment of paw volume was always performed in double blind and by the same operator. Indomethacin was administered p.o. as a reference drug. The increased percentage of edema was calculated as follows:

$$
\text { Increased edema }(\%)=\frac{\text { Volume at the end of } 3 h(m L)}{\text { Basal paw volume }(m L)} \times 100
$$

The percentage inhibition of edema for each group was calculated by the following formula 


$$
\mathrm{P} \%(\text { Inhibition of edema })=\frac{E c-E t}{E c} \times 100
$$

$\mathrm{Ec}=\%$ Edema of the negative control group, and $\mathrm{Et}=\%$ Edema of the treatment group.

\section{Carrageenan-induced mechanical hyperalgesia}

Mechanical hyperalgesia was examined in an inflammatory pain rat model by measuring the withdrawal thresholds of hind paw to an increasing pressure stimulus, using an analgesymeter (model 37,215; Ugo Basile, Italy). Paw withdrawal thresholds were measured in naive animals prior to the intraplantar injection of carrageenan into the hind paw. The cut-off was set at $250 \mathrm{~g}$ and the endpoint was taken as paw withdrawal or vocalization. Withdrawal thresholds were measured before (predose) and up to $3 \mathrm{~h}$ after drug or vehicle administration (postdose). In all cases, testing was done in blind. Reversal of mechanical hyperalgesia was calculated according to the following formula [27]:

$$
\% \text { Reversal }=\frac{\text { Postdose threshold }- \text { Predose threshold }}{\text { Naive threshold }- \text { Predose threshold }} \times 100
$$

\section{Carrageenan-induced thermal hyperalgesia}

Carrageenan-induced thermal hyperalgesia was assessed in separate groups of animals. The measurement of the nociceptive response to a thermal stimulus used a hotplate test with the temperature adjusted to $51 \pm 1{ }^{\circ} \mathrm{C}$ [28]. The withdrawal latencies of the hind paw were measured. Hyperalgesia to heat was defined as a decrease in the $\Delta$ latency (sec), calculated by the difference of latency times between the carrageenan- and noninjected paw (naive). $\mathrm{BuOH}$ fraction was administered orally at the dose of $120 \mathrm{mg} / \mathrm{kg}$ one hour before the carrageenan injection, and the positive control group received indomethacin $(10 \mathrm{mg} / \mathrm{kg}$, p.o.).

\section{Urate-induced synovitis}

One hour after the drug administration, rats were anesthetized and injected with $100 \mu \mathrm{L}$ of sodium urate crystals into one knee. The animals were allowed to walk on a metal grid after 18-24 h. A scoring system is adopted in which inflammatory symptoms ranging from tenderness, limping, occasional 3-legged gait to complete 3-legged gait are scored from $1+$ to $4+$ [29]. $\mathrm{BuOH}$ fraction was administered orally at the dose of $120 \mathrm{mg} / \mathrm{kg} 1 \mathrm{~h}$ before and $20 \mathrm{~h}$ after the urate injection, and the positive control group received indomethacin $(10 \mathrm{mg} / \mathrm{kg}$, p.o.).

\section{Statistical data analysis}

Data are expressed in mean \pm standard error of the mean (SEM) from eight animals per group. Statistical analysis was performed by one-way analysis of variance
(ANOVA). Dunnett's multiple range test was performed to determine significant differences among means. Kruskal-Wallis test was used to analyze non-parametric data, followed by Mann- Whitney $U$ test if applicable. The values of $p<0.05$ were considered to be statistically significant.

\section{Determination of total phenolic content}

Total phenolic content was measured using the Folin-Ciocalteau method as described previously [25].

\section{Characterization of phenolic compounds}

Phenolic compounds in the $\mathrm{BuOH}$ fraction were analyzed by a Shimadzu HPLC system equipped with a DAD detector and $\mathrm{C}_{18}$ column $(250 \times 4.6 \mathrm{~mm} ; 5 \mu \mathrm{m})$, using a gradient of $\mathrm{MeOH}$ (solvent $\mathrm{A}$ ) and $0.1 \%$ phosphoric acid in water (solvent B) as mobile solvents. The following HPLC method was used: flow rate $(0.6 \mathrm{~mL} / \mathrm{min}) ; 0-5 \mathrm{~min}(10 \%$ A); 5-7 $\min (10-25 \% \mathrm{~A}) ; 7-20 \min (25 \% \mathrm{~A}) ; 20-40 \mathrm{~min}$ (25-50\% A); $40-55 \min (50 \% \mathrm{~A}) ; 55-63 \min (50-80 \% \mathrm{~A})$; 63-68 $\min (80-100 \% \mathrm{~A})$. The compounds isolated were identified by comparison of their retention time $\left(t_{\mathrm{R}}\right)$ and spectroscopic data (UV and ${ }^{1} \mathrm{H}$ - and ${ }^{13} \mathrm{C}-\mathrm{NMR}$ ) with those of reference compounds [25].

\section{Results}

\section{Effect of CEE on serum uric acid levels in rats}

The CEE at 300,600 , and $1200 \mathrm{mg} / \mathrm{kg}$ were orally administered for 5 days on oxonate-induced hyperuricemia rats, and serum uric acid levels were measured by the phosphotungstic acid method. As presented in Table 1, compared with the uric acid value of the normal rats $(116.17 \mu \mathrm{mol} / \mathrm{L})$, the value of the control rats $(218.66 \mu \mathrm{mol} / \mathrm{L})$ was significantly increased by the injection of potassium oxonate $(p<0.01)$. Administration of the CEE enabled lowering the uric acid levels of hyperuricemic rats to normal ranges at 600 and $1200 \mathrm{mg} / \mathrm{kg}$ $(p<0.05)$, while no effect was observed at dose of $300 \mathrm{mg} / \mathrm{kg}$. The positive control, allopurinol at dose of $10 \mathrm{mg} / \mathrm{kg}$, displayed more extensive hypouricemic activity, which significantly reduced the serum uric acid level to $101.69 \mu \mathrm{mol} / \mathrm{L}(p<0.01)$.

\section{Effect of CEE and BuOH fraction on serum uric acid levels in rats}

A part of CEE (150 g) was fractionated, and obtained $30 \mathrm{~g}$ of the $\mathrm{BuOH}$-soluble portion. The CEE $(600 \mathrm{mg} / \mathrm{kg})$ and $\mathrm{BuOH}$ fraction $(120 \mathrm{mg} / \mathrm{kg})$ were further tested for hypouricemic activity in an animal model, and were orally administered for 5 days on oxonate-induced hyperuricemia rats, and the serum uric acid levels were measured by the phosphotungstic acid method. As presented in Table 2, the $\mathrm{CEE}$ and $\mathrm{BuOH}$ fr. of $S$. orientalis reduced uric acid levels. Of the samples tested, the $\mathrm{BuOH}$ fr. exhibited 
Table 1 Inhibitory effect of crude ethanol extract (CEE) from S. orientalis on serum uric acid levels in rats

\begin{tabular}{lllll}
\hline Group treatment & $\begin{array}{l}\text { Dose } \\
(\mathrm{mg} / \mathrm{kg})\end{array}$ & Number & $\begin{array}{l}\text { Serum uric acid } \\
\text { levels }(\mu \mathrm{mol} / \mathrm{L})\end{array}$ & $\begin{array}{l}\text { Inhibition } \\
(\%)\end{array}$ \\
\hline Normal & & & $116.17 \pm 8.71$ & \\
Control & & 8 & $218.66 \pm 16.82^{\# \#}$ & \\
CEE & 300 & 8 & $174.49 \pm 12.31$ & 20.2 \\
& 600 & 8 & $159.16 \pm 16.36^{*}$ & 27.2 \\
& 1200 & 8 & $158.18 \pm 14.07^{*}$ & 27.7 \\
Allopurinol & 10 & 8 & $101.69 \pm 15.98^{* *}$ & 53.5 \\
\hline
\end{tabular}

Hyperuricemic rats were induced by a potassium oxonate injection $1 \mathrm{~h}$ before the last drug administration. The CEE at 300,600 and $1200 \mathrm{mg} / \mathrm{kg}$ and allopurinol at $10 \mathrm{mg} / \mathrm{kg}$ were orally administrated once a day for five consecutive days. The control and normal groups were orally administered with $0.5 \%$ CMC-Na. The serum uric acid levels of rats were measured by the phosphotungstic acid method. Values are displayed as mean \pm SEM ${ }^{*} p<0.05,{ }^{* *} p<0.01$ vs. hyperuricemic rats (control); $\# p<0.05, \# \# p<0.01$ vs. normal rats

notable hypouricemic activity by lowering the serum uric acid level by $31.4 \%$ at dose of $120 \mathrm{mg} / \mathrm{kg}(p<0.01)$.

\section{Effect of BuOH fraction on XO activity in rats}

Detailed investigation for hypouricemic activity of the $\mathrm{BuOH}$ fraction was subsequently carried out with in vivo test for liver $\mathrm{XO}$ activity in rats. As shown in Fig. 1 , the values observed for $\mathrm{XO}$ activity in the control and $\mathrm{BuOH}$ fr. (120 mg/kg p.o.) groups were $2.08 \pm 0.20$ and $1.40 \pm 0.14 \mathrm{mmol} / \mathrm{min}$ per $\mathrm{mg}$ protein, respectively. It means that an in vivo inhibition of XO by $32.7 \%$ was observed for the $\mathrm{BuOH}$ fr. as compared to the control group $(p<0.05)$. In the same experiment, allopurinol inhibited XO activity (41.8\% inhibition) at the dose of $10 \mathrm{mg} / \mathrm{kg}$, showing slightly more potent activity than the $\mathrm{BuOH}$ fr.

Table 2 Inhibitory effect of crude ethanol extract (CEE) and $\mathrm{BuOH}$ fraction (BuOH fr.) from S. orientalis on serum uric acid levels in rats

\begin{tabular}{lllll}
\hline Group treatment & Number & $\begin{array}{l}\text { Dose } \\
(\mathrm{mg} / \mathrm{kg})\end{array}$ & $\begin{array}{l}\text { Serum uric acid } \\
\text { levels }(\mu \mathrm{mol} / \mathrm{L})\end{array}$ & $\begin{array}{l}\text { Inhibition } \\
(\%)\end{array}$ \\
\hline Normal & 8 & & $114.54 \pm 11.23$ & \\
Control & 8 & & $222.38 \pm 24.58^{\# \#}$ & \\
CEE & 8 & 600 & $163.58 \pm 12.94^{*}$ & 26.4 \\
BuOH fr. & 8 & 120 & $152.47 \pm 11.68^{* *}$ & 31.4 \\
Allopurinol & 8 & 10 & $115.28 \pm 11.13^{* *}$ & 48.2 \\
\hline
\end{tabular}

Hyperuricemic rats were induced by a potassium oxonate injection $1 \mathrm{~h}$ before the last drug administration. The CEE at $600 \mathrm{mg} / \mathrm{kg}$, the BuOH fr. at $120 \mathrm{mg}$ and allopurinol at $10 \mathrm{mg} / \mathrm{kg}$ were orally administrated once a day for five consecutive days. The control and normal groups were orally administered with $0.5 \%$ CMC-Na. The serum uric acid levels of rats were measured by the phosphotungstic acid method. Values are displayed as mean \pm SEM ${ }^{*} p<0.05,{ }^{* *} p<0.01$ vs. hyperuricemic rats (control);

$\# p<0.05, \# \# p<0.01$ vs. normal rats

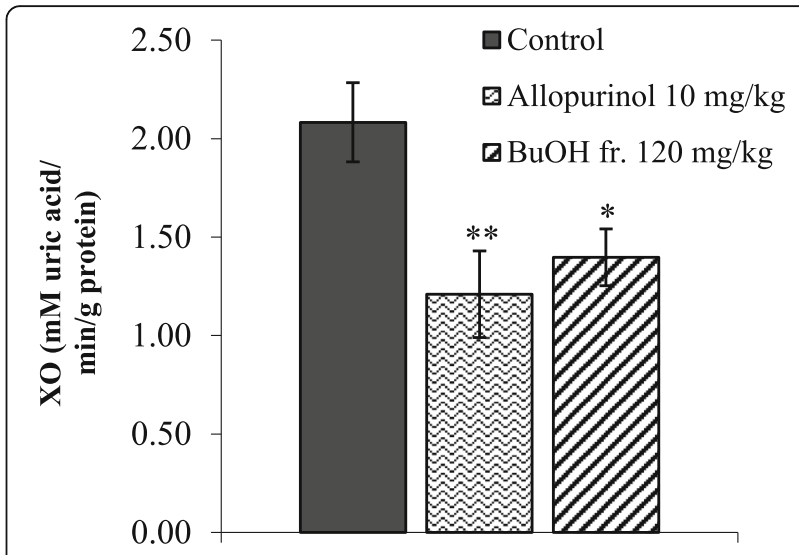

Fig. 1 Xanthine oxidase $(X O)$ enzyme from rat liver was treated with the $\mathrm{BuOH}$ fraction (BuOH fr.). The activity of $\mathrm{XO}$ inhibition was evaluated by monitoring uric acid formation using the spectrophotometric method. Allopurinol was used as a reference agent. Values are presented as $\mathrm{mmol} / \mathrm{min}$ per $\mathrm{g}$ protein and mean \pm SEM from 8 animals in the treatment group. ${ }^{*} p<0.05$, ${ }^{* *} p<0.01$ vs. control

\section{Effect of $\mathrm{BuOH}$ fraction on paw edema in rats}

Anti-inflammatory activity of the $\mathrm{BuOH}$ fraction was evaluated using a carrageenan-induced paw edema model. Intraplantar injection of carrageenan $(1 \% \mathrm{w} / \mathrm{v})$ markedly increased paw volume of the rats, reaching its maximal effect after $3 \mathrm{~h}$ (Fig. 2). Treatment with the $\mathrm{BuOH}$ fr. $(120 \mathrm{mg} / \mathrm{kg})$ reduced the volume of paw edema by $30.4 \%(p<0.05)$, as compared to the maximum volume measured before the treatment. Indomethacin $(10 \mathrm{mg} / \mathrm{kg})$ served as a positive control, displaying inhibitory activity by reducing $44.6 \%$ paw edema.

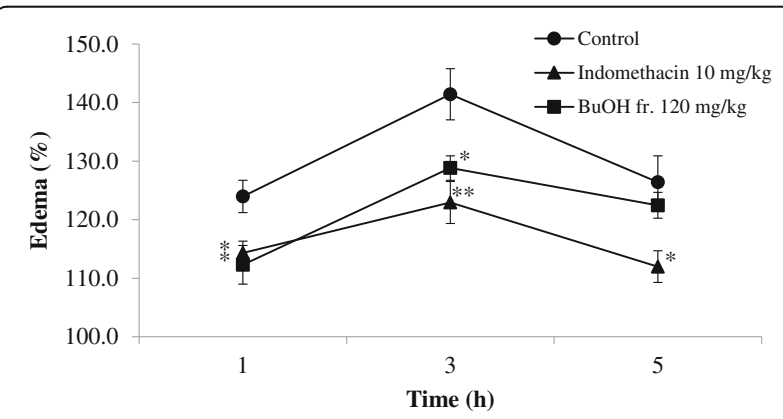

Fig. 2 The $\mathrm{BuOH}$ fraction (BuOH fr.) was suspended in distilled water and orally administered. Paw edema was induced 30 min after the subplantar injection of $1 \%(w / V)$ carrageenan in buffer saline. The paw edema was measured before (predose) and at intervals of 1, 3, and $5 \mathrm{~h}$ after the carrageenan injection. Indomethacin was used as a reference agent. Values are expressed in percent increase of paw before the carrageenan injection and mean \pm SEM from 8 animals in the treatment group. ${ }^{*} p<0.05,{ }^{* *} p<0.01$ vs. control 


\section{Effect of BuOH fraction on mechanical hyperalgesia in rats}

Figure 3 shows the data obtained in rats while mechanical hyperalgesia was induced by carrageenan, which led to the reduction of ipsilateral paw withdrawal thresholds approximately from $150 \mathrm{~g}$ to $45-55 \mathrm{~g}$ after the injection in naive animals (data not shown). Administration of the $\mathrm{BuOH}$ fraction or indomethacin significantly reversed inflammatory mechanical hyperalgesia (Fig. 3a). A maximal 32\% reversal was observed $3 \mathrm{~h}$ after the administration of the $\mathrm{BuOH} \mathrm{fr}$. at dose of $120 \mathrm{mg} / \mathrm{kg}(p<0.05)$, while the positive control (indomethacin) produced up to $44 \%$ reversal (Fig. $3 \mathrm{~b}$ ).

\section{Effect of BuOH fraction on thermal hyperalgesia in rats} Carrageenan injection into the hind paw of rats induced thermal hyperalgesia, exerting maximal effect after $3 \mathrm{~h}$. As shown in Fig. 4, the $\mathrm{BuOH}$ fraction remarkably increased $\Delta$ withdrawal latency at dose of $120 \mathrm{mg} / \mathrm{kg}$.

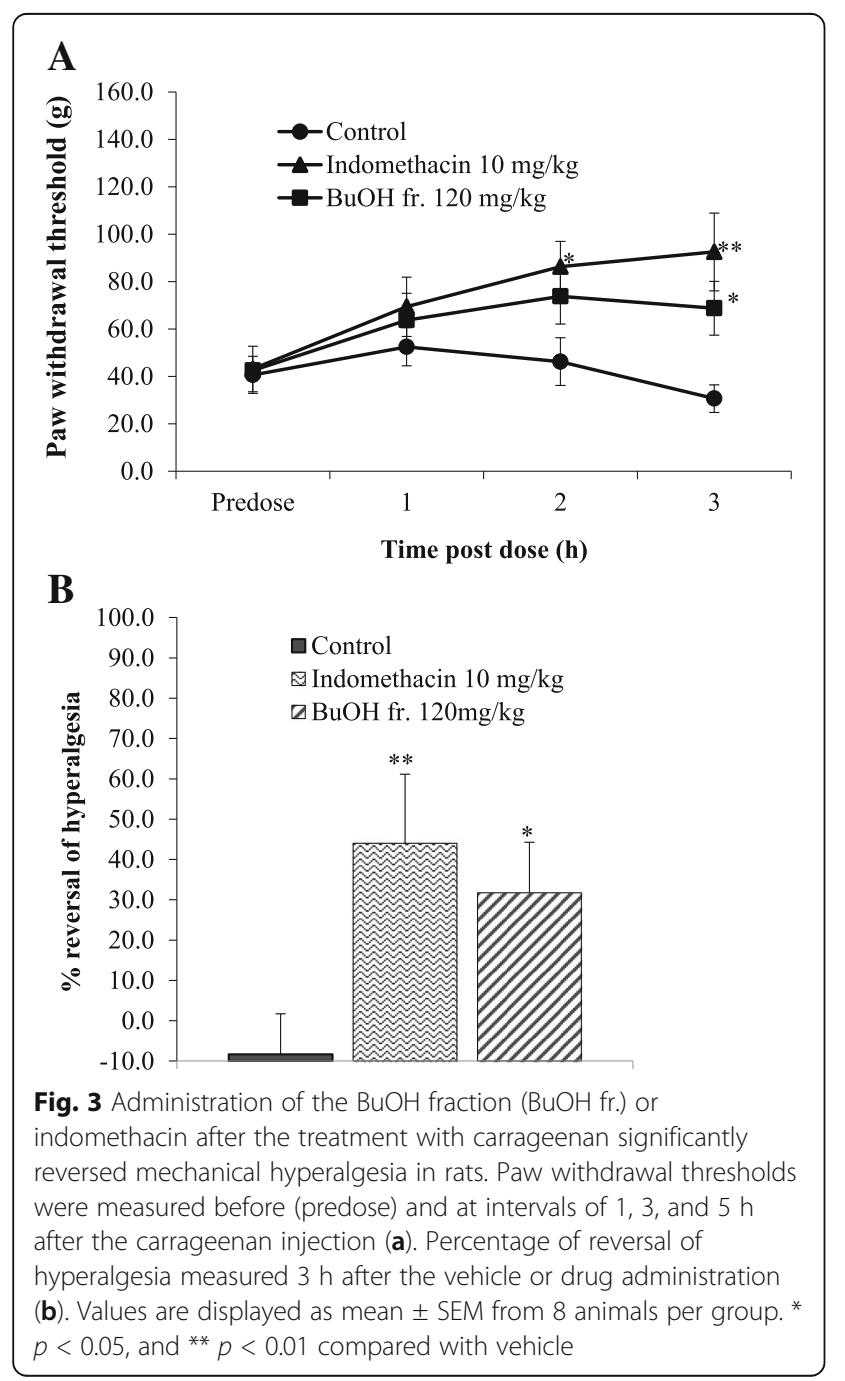

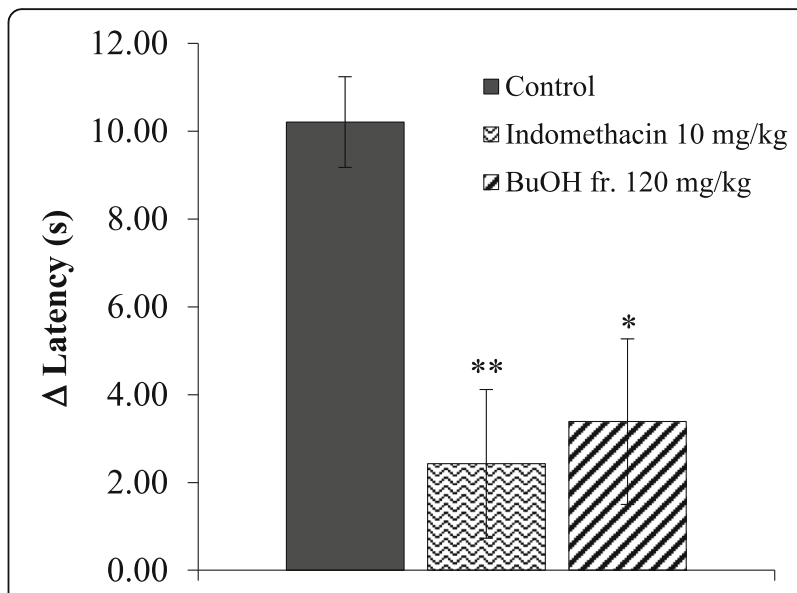

Fig. 4 Carrageenan was injected into the hind paw to produce thermal hyperalgesia in rats. The $\mathrm{BuOH}$ fraction (BuOH fr.) at the oral dose of $120 \mathrm{mg} / \mathrm{kg}$ significantly increased $\Delta$ withdrawal latency, inhibiting the inflammatory hyperalgesia response after $3 \mathrm{~h}$ of the treatment. Indomethacin $(10 \mathrm{mg} / \mathrm{kg})$ was used as a reference compound. Values are expressed in mean \pm SEM from 8 animals per group. ${ }^{*} p<0.05,{ }^{* *} p<0.01$ vs. hyperuricemic rats (control)

Indomethacin $(10 \mathrm{mg} / \mathrm{kg})$ also exhibited significant antinociceptive activity by reducing thermal hyperalgesia.

\section{Effect of BuOH fraction on synovitis}

The inflammatory response in the leg of rats occurred $5 \mathrm{~h}$ after intra-synovial injection of sodium urate crystal, and then was gradually increased during subsequent $13 \mathrm{~h}$ (data not shown). The hyperalgesic response was stable in all animals for $2 \mathrm{~h}$, prior to the second drug administration. Administration of the $\mathrm{BuOH}$ fraction $(120 \mathrm{mg} / \mathrm{kg}$, p.o.) alleviated urate-induced synovitis $20 \mathrm{~h}$ after injection of a causative inflammatory agent (Table 3). Indomethacin $(10 \mathrm{mg} / \mathrm{kg}$, p.o. $)$ also displayed anti-inflammatory effect in this model, resulting in leg tenderness for all animals in the group.

Table 3 Effect of BuOH fraction (BuOH fr.) on urate induced synovitis in rats

\begin{tabular}{llll}
\hline Group & Number & $\begin{array}{l}\text { Dose } \\
(\mathrm{mg} / \mathrm{kg} \mathrm{p.o.})\end{array}$ & Score \\
\hline Control & 8 & - & $3.5(2-4)$ \\
BuOH fr. & 8 & 120 & $2(1-3)^{*}$ \\
Indomethacin & 8 & 10 & $1(1-1)^{* *}$
\end{tabular}

Inflammatory responses in the leg receiving sodium urate began $5 \mathrm{~h}$ after the injection, and continued to increase during $13 \mathrm{~h}$ (data not shown).

Hyperalgesic responses were stable in all animals $2 \mathrm{~h}$ prior to the second drug administration. An anti-inflammatory agent was effective in this model. Values are expressed in median of score range ( $\mathrm{min}-\mathrm{max}$ ). The Kruskal-Wallis test was performed, followed by the Mann-Whitney $\mathrm{U}$ test ${ }^{*} p<0.05,{ }^{* *} p<0.01$ vs. control 


\section{Analysis of total phenolic content and identification of phenolic compounds}

Major constituents of the CEE were identified as phenolic compounds by analysis of the ${ }^{1} \mathrm{H}$ NMR data, and the corresponding signals were also detected in the $\mathrm{BuOH}$ fraction-the most active fraction of the extract. Kirenol is an anti-inflammatory diterpene reported previously from this plant [2], but its NMR signals were not present in the $\mathrm{BuOH}$ fraction. Therefore, transference of the phenolic compounds found in the CEE into the $\mathrm{BuOH}$ fraction was hypothesized to explain the retention of the biological properties. In line with this hypothesis, some phenolic compounds were reported to show anti-gout and anti-inflammatory activities [24, 3035]. Total phenolic contents for the organic solvent fractions (Hex, EtOAc, and $\mathrm{BuOH}$ fractions) and the CEE were quantitatively calculated to be $42.5,75.7$, 173.4 , and $138.1 \mathrm{mg} / \mathrm{g}$, respectively. The $\mathrm{BuOH}$ fraction, displaying the most potent biological activities, contained the highest total phenolic content, consistent with our hypothesis. The phenolic compounds were isolated by HPLC, and their spectroscopic data (Additional file 1) were compared with those published in the literature $[14,30]$ : the phenolic compounds were identified as 3CQA (1; 3-caffeoylquinic acid; $\left.t_{\mathrm{R}}=17.37 \mathrm{~min}\right), 5$-CQA (2; chlorogenic acid; $t_{\mathrm{R}}=22.32 \mathrm{~min}$ ), 5-CQA (3; 4caffeoylquinic acid; $\left.t_{\mathrm{R}}=23.10 \mathrm{~min}\right)$, caffeic acid (4, $\left.t_{\mathrm{R}}=27.92 \mathrm{~min}\right)$, diCQAs $(5 ; 3,4$-dicaffeoylquinic acid, 3,5-dicaffeoylquinic acid, 3,4-dicaffeoylquinic acid; $t_{\mathrm{R}}=43.41 \mathrm{~min}, 45.02 \mathrm{~min}$, and $45.38 \mathrm{~min}$, respectively), rutin $\left(6 ; t_{\mathrm{R}}=46.86 \mathrm{~min}\right)$, quercitrin $\left(7 ; t_{\mathrm{R}}=49.01 \mathrm{~min}\right)$, kaempferol-3-O-rutinoside $\left(8 ; t_{\mathrm{R}}=50.94 \mathrm{~min}\right)$, and kaempferol-3-O-rhamnoside (9; $\left.t_{\mathrm{R}}=55.63 \mathrm{~min}\right)$ (Fig. 5).

\section{Discussion}

Gout is an emerging and common metabolic disorder closely related to hyperuricemia, the treatment of which aims to relieve acute gouty attacks and to prevent recurrent gouty episodes. Therapeutic approaches for treating gout include applications of anti-inflammatory agents for symptomatic relief, as well as selective inhibition of the terminal steps in uric acid biosynthesis for chronic gout [19]. Combination of the relevant therapies, such as lowering uric acid levels, inhibiting inflammatory responses, and modifying dietary behaviors, was suggested for the treatment of gout [36]. Suppression of XO activity is one of the therapeutic strategies to reduce blood uric acid levels. However, only a few XO inhibitors, e.g., allopurinol and febuxostat, have been clinically used [37]. Although most of the Vietnamese traditional remedies for curing gout disease contain hy-thiem [1, 3], pharmacological research of this medicinal plant associated with the treatment of this metabolic and inflammatory disorder has been underexplored.
We demonstrated in this study that CEE of hy-thiem significantly reduced uric acid levels in oxonate-induced hyperuricemia rats. In addition, in vitro inhibitory activity of the CEE on $\mathrm{XO}$ was observed. The most potent activity was detected for the $n-\mathrm{BuOH}$-soluble portion. Among the fractions resulting from activity-guided fractionation, the $\mathrm{BuOH}$ fraction presented $\mathrm{XO}$ inhibitory activity even more potent than that of the whole crude extract (data not shown), and showed no acute and sub-chronic toxicity (Additional file 2). Therefore, transference of active components from the $\mathrm{CEE}$ to the $\mathrm{BuOH}$ fraction was suggested. The $\mathrm{BuOH}$ fraction of hy-thiem showed its hypouricemic effect at dose of $120 \mathrm{mg} / \mathrm{kg}$. Subsequent in vivo studies at the same dose also revealed that the $\mathrm{BuOH}$ fraction remarkably inhibited liver $\mathrm{XO}$ activity in rats. These observations suggested that the hypouricemic effect of hy-thiem is caused by, at least in part, its inhibitory potency on $\mathrm{XO}$, a key enzyme in the biosynthetic pathway of uric acid. Furthermore, the $\mathrm{BuOH}$ fraction also displayed a notable anti-inflammatory and antinociceptive activities in the carrageenan-induced animal model, as shown previously with the crude extract of $S$. orientalis [5, 9]. Finally, deposition of urate crystals, an important initiation factor in the inflammatory process of gout, has been taken into consideration in our experiments. The $\mathrm{BuOH}$ fraction was found to have anti-inflammatory effect in the urate-induced synovitis model, which represents acute gouty attacks, confirming that the inhibition of $\mathrm{XO}$ is associated with anti-inflammatory responses [37].

Although kirenol was reported to be responsible for the anti-inflammatory and analgesic activities of S. orientalis [2], it was absent in the $n$ - $\mathrm{BuOH}$-soluble fraction in the present study. Instead, phenolic compounds were identified as major components of the fraction. Therefore, the anti-gout and anti-inflammatory effects of hy-thiem were presumed to be associated with those phenolic compounds in the $\mathrm{BuOH}$ fraction $[32,38]$. The major constituents in this fraction were identified as caffeic acid analogues (1-5) and flavonones (6-9). Many studies have showed uricemia lowering and antiinflammatory activities of caffeic acid analogues [31-34] and flavonones [24, 35], supporting our hypothesis. This is the first report of this plant that phenolic compounds 1-9 are the major constituents, showing antiinflammatory, analgesic, and anti-gout activities. Of these phenolic compounds, 3-CQA (1), chlorogenic acid (2), 4-CQA (3), di-CQA (5), quercitrin (7), kaempferol3-O-rutinoside (8), and kaempferol-3-O-rhamnoside (9) were identified for the first time from this species, while a few other phenolic metabolites including caffeic acid (4) and rutin (6) were reported previously [14]. 
A

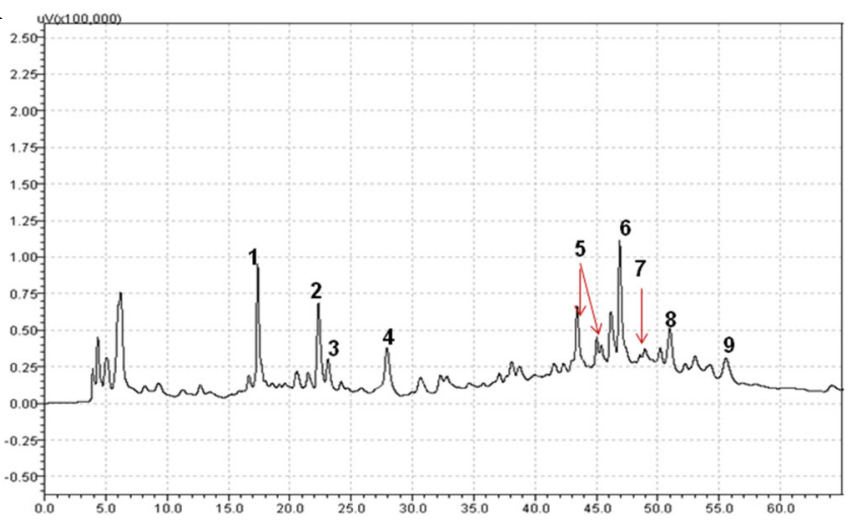

B<smiles>[R][CH]C1CC[C@@H](CCC(=O)O)C[C@H]1O</smiles>

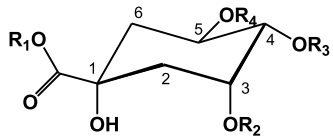<smiles>CC(=O)CCC1CCC(O)C(O)C1</smiles><smiles>[R20]OC1C(=O)C2C(=CC(O)CC2O)OC1C1CCC(O)C([R])C1</smiles>

$1 \quad \mathrm{R}_{2}=$ Caffeoyl, $\mathrm{R}_{1}=\mathrm{R}_{3}=\mathrm{R}_{4}=\mathrm{H}$

$2 \mathrm{R}_{4}=$ Caffeoyl, $\mathrm{R}_{1}=\mathrm{R}_{2}=\mathrm{R}_{3}=\mathrm{H}$

$3 \quad \mathrm{R}_{3}=$ Caffeoyl, $\mathrm{R}_{1}=\mathrm{R}_{2}=\mathrm{R}_{4}=\mathrm{H}$

$5 \quad \mathrm{R}_{3}=\mathrm{R}_{4}=$ Caffeoyl, $\mathrm{R}_{1}=\mathrm{R}_{2}=\mathrm{H}$ $\mathrm{R}_{2}=\mathrm{R}_{4}=$ Caffeoyl, $\mathrm{R}_{1}=\mathrm{R}_{3}=\mathrm{H}$ $\mathrm{R}_{2}=\mathrm{R}_{3}=$ Caffeoyl, $\mathrm{R}_{1}=\mathrm{R}_{4}=\mathrm{H}$

$6 \mathrm{R}_{1}=$ Rutinose, $\mathrm{R}_{2}=\mathrm{OH}$

$7 \quad \mathrm{R}_{1}=$ Rhamnoside, $\mathrm{R}_{2}=\mathrm{OH}$

$8 \mathrm{R}_{1}=$ Rutinose, $\mathrm{R}_{2}=\mathrm{H}$

$9 \mathrm{R}_{1}=$ Rhamnoside, $\mathrm{R}_{2}=\mathrm{H}$

Fig. 5 Chromatogram (HPLC-DAD, UV $255 \mathrm{~nm}$ ) of the BuOH fraction (a) and the corresponding chemical structures (b)

\section{Conclusions}

This study demonstrates that crude ethanol extract and its $\mathrm{BuOH}$-soluble portion from $\mathrm{S}$. orientalis (Vietnamese hythiem) show anti-hyperuricemic and anti-inflammatory activities experimentally. The active constituents responsible for the biological activities were identified as phenolic compounds. Our findings support the application of this plant as an indigenous medicine for treating gout, which occurs when metabolic and inflammatory disorders take place together, by its dual pharmacological action.

\section{Additional files}

Additional file 1: Spectroscopic data for phenolic compounds from hythiem (Siegesbeckia orientalis). (DOCX $17 \mathrm{~kb}$ )

Additional file 2: Report on toxicity study of BuOH fraction. (DOCX $104 \mathrm{~kb}$ )

\section{Acknowledgements}

We are grateful to Doctor Nguyen Quynh Chi, Department of Pharmacognosy, Hanoi University of Pharmacy for collecting and providing plant samples.

\section{Funding}

The authors deeply acknowledge the Vietnam National Foundation for Science and Technology Development (NAFOSTED) for providing research grant (No 106.99-2012.90). This research was supported by the research fund of Chungnam National University and the Priority Research Centers Program (NRF-2009-0093815) through the National Research Foundation of Korea (NRF) grant funded by Korean Government.

\section{Availability of data and materials}

All data and materials related to this study are included in the manuscript and supplementary files.

\section{Authors' contributions}

PTT, NHA, and MN designed the study, and NTD carried out the experiment. NTD, $\mathrm{HH}, \mathrm{HTKH}$, and NMK performed data analysis and prepared the manuscript. All authors have read and approved the final version of this manuscript.

\section{Competing interests}

The authors declare that they have no competing interests.

\section{Consent for publication}

Not applicable. 


\section{Ethics approval and consent to participate}

All experimental protocols on animals in this study were approved by the Scientific and Ethical Committee of Hanoi University of Pharmacy (156/DHN-QD).

\section{Publisher's Note}

Springer Nature remains neutral with regard to jurisdictional claims in published maps and institutional affiliations.

\section{Author details \\ 'Department of Pharmacology, Hanoi University of Pharmacy, 13 Le Thanh Tong, Hoan Kiem, Hanoi, Vietnam. ${ }^{2}$ Department of Pharmaceutical Analysis and Standardization, National Institute of Medicinal Materials, 3B Quang Trung, Hoan Kiem, Hanoi, Vietnam. ${ }^{3}$ College of Pharmacy, Woosuk University, Wanju, Jeonbuk 55338, Republic of Korea. ${ }^{4}$ College of Pharmacy, Chungnam National University, Yuseong-gu, Daejeon 34134, Republic of Korea.}

\section{Received: 30 August 2016 Accepted: 21 March 2017}

\section{Published online: 04 April 2017}

\section{References}

1. NIMM. (National Institute of Medicinal Materials of Vietnam). Medicinal Plant Resource of Vietnam. Hanoi: Science and Technology Publishing House; 1993.

2. Wang JP, Zhou YM, Ye YJ, Shang XM, Cai YL, Xiong CM, Wu YX, Xu HX. Topical anti-inflammatory and analgesic activity of kirenol isolated from Siegesbeckia orientalis. J Ethnopharmacol. 2011:137:1089-94.

3. Do TL. Vietnamese Medicinal Plants and Remedies. Hanoi: Hong Duc Publishing House; 2012.

4. Vo VC. The Dictionary of Vietnamese Medicinal Plant. Hochiminh: Medical Publishing House; 2012.

5. Zhang ZF, Yang LR, Li YB, Yan LH. Summary on chemical composition and pharmacological action of Herba Siegesbeckiae. Inf Tradit. Chin. Med. 2006;23:15-7.

6. Xiang Y, Zhang H, Fan CQ, Yue JM. Novel diterpenoids and diterpenoid glycosides from Siegesbeckia orientalis. J Nat Prod. 2004;67:1517-21.

7. Giang PM, Son PT, Otsuka H. ent-pimarane-type diterpenoids from Siegesbeckia orientalis L. Chem Pharm Bull. 2005;53:232-4.

8. Wang F, Cheng XL, Li YJ, Shi S, Liu JK. ent-Pimarane diterpenoids from Siegesbeckia orientalis and structure revision of a related compound. J Nat Prod. 2009;72:2005-8.

9. Hong Y-H, Weng L-W, Chang C-C, Hsu H-F, Wang C-P, Wang S-W, Houng JY. Anti-inflammatory effects of Siegesbeckia orientalis ethanol extract in in vitro and in vivo models. Biomed Res Int. 2014;2014:329712.

10. Busso N, So A. Gout: mechanisms of inflammation in gout. Arthritis Res Ther. 2010;12:206.

11. Zdero C, Bohlmann F, King RM, Robinson H. Sesquiterpene lactones and other constituents from Siegesbeckia orientalis and Guizotia scabra. Phytochemistry. 1991:30:1579-84

12. Xiang Y, Fan CQ, Yue JM. Novel sesquiterpenoids from Siegesbeckia orientalis. Helv Chim Acta. 2005:88:160-70.

13. Wang LL, Hu LH. Chemical constituents of Siegesbeckia orientalis L. J Integr Plant Biol. 2006;48:991-5.

14. Le TKN. Study on chemical constituents with antioxidant and antimicrobial activities from the Vietnamese plants hy thiem (Siegesbeckia orientalis L.) and bon-bot (Glochidion eriocarpum Champ.). Hanoi: Doctorate thesis, College of Chemistry, Hanoi National University; 2001.

15. Masuda T, et al. Identification of a potent xanthine oxidase inhibitor from oxidation of caffeic acid. Free Radic Biol Med. 2010;69:300-7.

16. Masuoka N, Kubo I. Suppression of superoxide anion generation catalyzed by xanthine oxidase with alkyl caffeates and the scavenging activity. Int J Food Sci Nutr. 2016:67:283-7.

17. Nguyen MT, et al. Xanthine oxidase inhibitory activity of Vietnamese medicinal plants. Biol Pharm Bull. 2004;27:1414-21.

18. Huang J, et al. Effects of Genistein, Apigenin, Quercetin, Rutin and Astilbin on serum uric acid levels and xanthine oxidase activities in normal and hyperuricemic mice. Food and Chem Toxicol. 2011;49:1943-7.

19. Emmerson BT. The management of gout. N Engl J Med. 1996;334:445-51.

20. Cao H, Pauff JM, Hille R. X-ray crystal structure of a xanthine oxidase complex with the flavonoid inhibitor quercetin. J Nat Prod. 2014;77:1693-9.

21. Zimmermann M. Ethical considerations in relation to pain in animal experimentation. Acta Physiol Scand Suppl. 1986;554:221-33.
22. Stavric B, Clayman S, Gadd RE, Hébert D. Some in vivo effects in the rat induced by chlorprothixene and potassium oxonate. Pharmacol Res Commun. 1975;7:117-24.

23. Carroll JJ, Roberta Douglass HC, Babson AL. A simplified alkaline phosphotungstate assay for uric acid in serum. Clin Chem. 1971;17:158-60.

24. Mo SF, Zhou F, Yao-Zhong LV, Hu QH, Zhang DM, Kong LD. Hypouricemic action of selected flavonoids in mice: Structure-activity relationships. Biol Pharm Bull. 2007;30:1551-6.

25. Lowry OH, Rosebrough NJ, Farr AL, Randall RJ. Protein measurement with folin-phenol reagent. J Biol Chem. 1951;193:265-75.

26. Winter CA, Risley EA, Nuss GW. Carrageenin-induced edema in hind paw of rats as an assay for anti-inflammatory drugs. Proc Soc Exp Biol Med. 1962;111:544-7.

27. Walker KM, Urban L, Medhurst SJ, Patel S, Panesar M, Fox AJ, Mcintyre P. The VR1 antagonist capsazepine reverses mechanical hyperalgesia in models of inflammatory and neuropathic pain. J Pharm Experimental Therapeutics. 2003;304:56-62.

28. Safieh-Garabedian B, Kanaan SA, Haddad JJ, Jaoude PA, Jabbur SJ, Saadé NE. Involvement of interleukin-1ß, nerve growth factor and prostaglandin E2 in endotoxin-induced localized inflammatory hyperalgesia. Br J Pharmacol. 1997;121:1619-26.

29. Urban L, Campbell EA, Gentry C, Patel S, Chaudry N, James I. Pharmacological profile of SDZ 249-665, a novel capsaicin agonist. Pain. 2000;89:65-74.

30. Thuong PT, Su ND, Ngoc TM, Hung TM, Dang NH, Thuan ND, Bae KH, Oh WK. Antioxidant activity and principles of Vietnamese bitter tea llex kudingcha. Food Chem. 2009;113:139-45.

31. Nguyen MT, Awale S, Tezuka Y, Shi L, Zaidi SF, Ueda JY, Tran QL, Murakami $Y$, Matsumoto K, Kadota S. Hypouricemic effects of acacetin and 4,5-Odicaffeoylquinic acid methyl ester on serum uric acid levels in potassium oxonate-pretreated rats. Biol Pharm Bull. 2005;28:2231-4.

32. Yonathan M, Asres K, Assefa A, Bucar F. In vivo anti-inflammatory and antinociceptive activities of Cheilanthes farinosa. J Ethnopharmacol. 2006;108:462-70.

33. Han T, Li HL, Zhang QY, Han P, Zheng HC, Rahman K, Qin LP. Bioactivityguided fractionation for anti-inflammatory and analgesic properties and constituents of Xanthium strumarium L. Phytomedicine. 2007:14:825-9.

34. Masuda T, Shingai $Y$, Takahashi C, Inai M, Miura Y, Honda S, Masuda A. Identification of a potent xanthine oxidase inhibitor from oxidation of caffeic acid. Free Radic Biol Med. 2014;69:300-7.

35. Zhu JX, Wang Y, Kong LD, Yang C, Zhang X. Effects of Biota orientalis extract and its flavonoid constituents, quercetin and rutin on serum uric acid levels in oxonate-induced mice and xanthine dehydrogenase and xanthine oxidase activities in mouse liver. J Ethnopharmacol. 2004:93:133-40.

36. Cannella AC, Mikuls TR. Understanding Treatments for Gout. Am J Manag Care. 2005;11(Suppl):S451-8.

37. Neogi T. Gout. New Eng J Med. 2011;364:443-5.

38. Ling $X$, Bochu WA. A review of phytotherapy of gout: perspective of new pharmacological treatments. Pharmazie. 2014;69:243-56.

\section{Submit your next manuscript to BioMed Central and we will help you at every step:}

- We accept pre-submission inquiries

- Our selector tool helps you to find the most relevant journal

- We provide round the clock customer support

- Convenient online submission

- Thorough peer review

- Inclusion in PubMed and all major indexing services

- Maximum visibility for your research

Submit your manuscript at www.biomedcentral.com/submit
Biomed Central 